\title{
High frequency of K-ras mutations in human colorectal hyperplastic polyps
}

K Otori, Y Oda, K Sugiyama, T Hasebe, K Mukai, T Fujii, H Tajiri, S Yoshida, $\mathrm{S}$ Fukushima, H Esumi

\begin{abstract}
Background-Hyperplastic polyps are common benign colorectal polyps, and are thought to have little association with malignant tumours in the colorectum. However, several reports suggest that some hyperplastic polyps may develop into colorectal neoplasms.

Aim-To clarify genetic alterations in colorectal hyperplastic polyps.

Methods-Twenty eight colorectal polyps having serrated components were resected from patients endoscopically. The $\mathrm{K}$-ras gene mutations in codons 12 and 13 were analysed by PCR-RFLP. Intranuclear p53 protein was immunostained by the avidin-biotin complex method.

Results-A mutation of the K-ras gene was detected in nine (47\%) of 19 hyperplastic polyps, and five $(56 \%)$ of nine adenomas. p53 protein nuclear accumulation was detected immunohistochemically in two $(22 \%)$ of nine adenomas, but not in any of the 19 hyperplastic polyps.

Conclusion-Some hyperplastic polyps may be true neoplastic lesions, and could be precursors of malignant neoplasia.

(Gut 1997; 40: 660-663)
\end{abstract}

Investigative Treatment Division K Otori K Sugiyama

H Esumi

Pathology Division, National Cancer Center Research Institute, East T Hasebe

K Mukai

Department of Internal Medicine, National Cancer Center Hospital East, 6-5-1 Kashiwanoha, Kashiwa, Chiba 277, Japan

Y Oda

T Fujii

Taiiri

$S$ Yoshida

First Department of Pathology, Osaka City University Medical School, 1-4-54, Asahi-machi, Abeno-ku, Osaka, 545, Japan S Fukushima

Correspondence to: Dr Hiroyasu Esumi Investigative Treatmen Division, National Cance Center Research Institute, East, 6-5-1 Kashiwanoha, Kashiwa, Chiba, 277, Japan. Accepted for publication 31 October 1996 ally regarded as neoplastic or premalignant lesions in the colon and rectum, and are not thought to have any malignant potential. However, coexisting adenomatous areas and hyperplasia in the same polyp have been reported. ${ }^{1-10}$ In addition, hyperplastic polyps are more common in colons harbouring adenomas or carcinomas. This previous evidence suggests that hyperplastic polyps are related to colorectal neoplasms, and in certain cases, polyps may progress to cancer, following the so-called hyperplasia-adenoma-adenocarcinoma sequence. ${ }^{5-7}$ By contrast, the adenoma-adenocarcinoma sequence is the major pathway of colorectal carcinogenesis, and is thought to be associated with the accumulation of mutations or deletions both in oncogenes and in tumour suppressor genes. ${ }^{11}$ Some mutations of various oncogenes and tumour suppressor genes may have already occurred, even in hyperplastic polyp-like early adenomas in the adenoma-adenocarcinoma sequence. ${ }^{11}$ To date, however, no mutation of these genes has been reported in hyperplastic polyps. To clarify the genetic changes in hyper- plastic polyps, we evaluated K-ras mutations and nuclear accumulation of p53 protein, which are common in colorectal adenomas and adenocarcinomas.

\section{Methods}

PATIENTS AND SPECIMENS

Twenty eight colorectal epithelial polyps were resected from patients undergoing colonoscopy during routine clinical practice at the National Cancer Center Hospital East from 1992 to 1995 . All specimens were fixed with $10 \%$ buffered formalin. The specimens were stained with Carszzi's haematoxylin for light stereomicroscopy. The pit patterns were classified according to Kudo's classification, ${ }^{12}$ and then embedded in paraffin wax. Each specimen was cut into $3 \mu \mathrm{m}$ sections, and stained with haematoxylin and eosin. Histological diagnoses were made using the World Health Organisation classification. ${ }^{13}$

PREPARATION OF DNA SAMPLES

Based on the histopathological findings in each case, polyp tissue was cut from three serial 5 $\mu \mathrm{m}$ thick sections, and after deparaffinisation with xylene and ethanol, the genomic DNA was extracted from the polyp tissue by serial digestions with proteinase $\mathrm{K}$ and $\mathrm{RNase} A .^{14}$ To prevent contamination, we used a new needle to microdissect every time. A sample of 1-2 $\mu 1$ of the DNA solution was used as a template for the polymerase chain reaction (PCR).
ANALYSIS OF K-ras MUTATION

Mutations in K-ras (codons 12 and 13) were screened by mismatched primer mediated PCR amplification for 40 cycles, followed by restriction fragment length polymorphism (RFLP) analysis using specific restriction endonucleases (PCR-RFLP) detected as described previously. ${ }^{14}$ For codon 12, PCR products encoding the wild type and mutant sequences were distinguished as 114 base pair (bp) and 143 bp fragments, respectively, by digestion with the restriction enzyme MvaI (Takara, Kyoto, Japan). For codon 13, the wild type was cleaved into $125 \mathrm{bp}$ and $32 \mathrm{bp}$ fragments by the restriction enzyme BglI (Takara, Kyoto, Japan), whereas the PCR product having the mutant sequence could not be digested by this enzyme. Human placental DNA (Sigma, St Louis, MO, USA) was used as a wild type control. And mutant DNA in codon 12 derived from the human colon adenocarcinoma cell line 
SW480 (American Type Culture Collection, Rockville, MD, USA) and DNA samples extracted from colorectal carcinomas, which were known to harbour a heterozygous point mutation at K-ras codon 13 (GGC to GAC; data not shown) were used as mutant controls. We always used aerosol resistant tips for PCR to prevent contamination. The mixtures with several ratios of mutant (SW480 DNA) to wild type (human placental) DNA were amplified by PCR to determine the sensitivity for detecting mutated K-ras gene. Mutation in K-ras is detectable by this method when mutated DNA comprised more than $10 \%$ of genomic DNA.

\section{DETECTION OF p53 PROTEIN}

All polyps were assessed for nuclear accumulation of p53 protein. Sections were deparaffinised, heated in a hot water bath at $90^{\circ} \mathrm{C}$ for 20 minutes in phosphate buffered saline (PBS), and then stained using a 1:1000 dilution of rabbit polyclonal antibody to human p53 protein, RSP53 (Nichirei, Tokyo, Japan), by the avidin-biotin-peroxidase complex method. Human lung carcinoma tissue, known to contain p53 protein, was used as a positive control (data not shown). When all epithelial cells of one crypt or more than $20 \%$ of 500 epithelial cells in a section were stained with the antibody, the polyp was scored as p53 positive.

\section{STATISTICAL ANALYSES}

Statistical analysis was performed using computer assisted Student's $t$ test with Stat View software for the Macintosh computer, version 4.0 (Abacus Concepts, Berkeley, CA, USA). A value of $\mathrm{p}<0.05$ was considered significant.

Clinicopathological data

\begin{tabular}{|c|c|c|c|c|c|c|}
\hline Case & Age & Sex & $\begin{array}{l}\text { Site of } \\
\text { polyp }\end{array}$ & $\begin{array}{l}\text { Size } \\
(\mathrm{mm})\end{array}$ & $\begin{array}{l}\text { Type } \\
\text { of pit }\end{array}$ & $\begin{array}{l}\text { K-ras mutation } \\
\text { (codon) }\end{array}$ \\
\hline \multicolumn{7}{|c|}{ Hyperplastic polyp: } \\
\hline 1 & 64 & $\mathrm{M}^{2}$ & A & 6 & a & 12 \\
\hline 2 & 61 & $\mathrm{~F}$ & A & 8 & a & 12 \\
\hline 3 & 57 & $\mathbf{M}$ & $\mathbf{R}$ & 5 & c & - \\
\hline 4 & 71 & $\mathrm{~F}$ & A & 6 & a & 12 \\
\hline 5 & 51 & $\mathrm{~F}$ & A & 5 & a & - \\
\hline 6 & 43 & $M$ & $\mathbf{R}$ & 4 & a & 12 \\
\hline 7 & 67 & $M$ & $\mathbf{R}$ & 2 & a & - \\
\hline 8 & 81 & $\mathrm{~F}$ & A & 4 & a & 12 \\
\hline 9 & 67 & M & $\mathrm{s}$ & 4 & a & 12 \\
\hline 10 & 43 & $M$ & $\mathrm{~T}$ & 8 & $\mathrm{a}$ & 13 \\
\hline 11 & 41 & M & $\mathbf{R}$ & 5 & a & - \\
\hline 12 & 71 & $M$ & A & 4 & a & - \\
\hline 13 & 60 & $\mathbf{M}$ & $\mathbf{R}$ & 6 & a & - \\
\hline 14 & 74 & $\mathbf{M}$ & C & 4 & a & - \\
\hline 15 & 59 & $M$ & $\mathbf{R}$ & 6 & a & - \\
\hline 16 & 61 & $M$ & $\mathbf{R}$ & 7 & a & 12 \\
\hline 17 & 77 & $\mathbf{F}$ & $\mathbf{R}$ & 4 & a & 12 \\
\hline 18 & 70 & $M$ & $\mathbf{R}$ & 3 & a & - \\
\hline 19 & 46 & $M$ & $\mathbf{R}$ & 4 & c & - \\
\hline \multicolumn{7}{|c|}{ Adenoma: } \\
\hline 1 & 68 & $M$ & $\mathbf{R}$ & 24 & $\mathrm{~g}$ & 12 \\
\hline 2 & 52 & $\mathbf{M}$ & C & 10 & a & 12 \\
\hline 3 & 79 & $\mathbf{M}$ & $\mathbf{R}$ & 4 & g & - \\
\hline 4 & 67 & M & $\mathbf{R}$ & 7 & $\mathrm{a}+\mathrm{g}$ & 12 \\
\hline 5 & 45 & $\mathrm{~F}$ & $\mathbf{R}$ & 8 & o & 12 \\
\hline 6 & 76 & $\mathbf{M}$ & $\mathbf{R}$ & 4 & g & - \\
\hline 7 & 56 & $\mathrm{~F}$ & $\mathrm{R}$ & 10 & a & 12 \\
\hline 8 & 66 & $\mathbf{M}$ & $S$ & 5 & $\mathrm{o}+\mathrm{g}$ & - \\
\hline 9 & 49 & $\mathbf{M}$ & $\mathbf{R}$ & 2 & $a^{\circ}$ & - \\
\hline
\end{tabular}

$\mathrm{C}=$ caecum; $\mathrm{A}=$ ascending colon; $\mathrm{T}=$ transverse colon; $\mathrm{S}=$ sigmoid colon; $\mathrm{R}=$ rectum; $\mathrm{a}=$ small and large asteroid pits; $\mathrm{o}=$ oval pit; $\mathrm{g}=$ =gyrus-like pit; $\mathrm{c}=$ cerebriform surface.

\section{Results}

The Table shows the clinicopathological characteristics of 28 colorectal polyps. The mean age of patients $(21$ men and seven women) was 61 years (ranging from 43 to 81 years). The incidence of polyps was higher in the rectum than in the colon. Histologically, 19 of 28 colorectal polyps were diagnosed as hyperplastic polyps, and nine of 28 as adenomas. Some hyperplastic polyps showed slightly elongated and stratified nuclei (Figure), but they could not be diagnosed as serrated adenomas. Seventeen hyperplastic polyps showed small or large asteroid pits. However, two hyperplastic polyps did not fit into Kudo's classification, and were tentatively called "cerebriform". Adenomas showed various pit patterns: asteroid, oval, gyrous-like pit, and a composite type (Table). All but the adenoma in case 1 were no more than $10 \mathrm{~mm}$ in diameter. The size of the adenomas (8.2 (SD) $6.5 \mathrm{~mm}$ ) was significantly larger than that of hyperplastic polyps $(5.0(1.6 \mathrm{~mm}) ; \mathrm{p}<0.05)$. On PCR-RFLP analysis, K-ras mutations in codon 12 were detected in eight $(42 \%)$ of 19 hyperplastic polyps and five $(56 \%)$ of nine adenomas; a K-ras mutation in codon 13 was detected in one (5\%) of 19 hyperplastic polyps; and no mutation in codon 13 was detected in adenomas. The total frequency of K-ras mutations was nine $(47 \%)$ of 19 hyperplastic polyps and five $(56 \%)$ of nine adenomas. Accumulation of $\mathrm{p} 53$ protein in the nuclei was found in two $(22 \%)$ of nine adenomas (cases 1 and 4); this was not found in any of the 19 hyperplastic polyps. APC gene mutations were searched for in the other seven colorectal hyperplastic polyps, but none was found.

\section{Discussion}

It is generally accepted that hyperplatic polyps are benign lesions without malignant potential and do not develop into colorectal neoplasms. Our study is the first to identify genetic alterations (K-ras mutations) in hyperplastic polyps of the colon and rectum. Similarly, K-ras mutation occurs in the hyperplastic foci of the pancreatic duct and hyperplastic aberrant crypt foci (ACF) of the colorectal epithelium, which are thought to be early precursor lesions of pancreatic and colorectal cancer. ${ }^{15-19}$ K-ras gene mutations may be responsible for the hyperplastic change, and may not contribute to immediate carcinogenesis of the pancreas and colorectum. However, K-ras mutations were identified in colorectal adenomas and adenocarcinomas, and are thought to play an important part in colorectal carcinogenesis. ${ }^{11}$ In this study, the frequency of K-ras mutation in hyperplastic polyps was similar to that of adenomas. Furthermore, hyperplastic polyps show positive staining for carcinoembryonic antigen (CEA) with greater intensity than the normal epithelium, increased bcl-2 expression on immunohistochemistry, and reduced secretion of O-acylated sialomucin, which are important features of colorectal neoplasia. ${ }^{20-22}$ Therefore, some hyperplastic polyps may be neoplastic lesions, and develop into colorectal tumours. 


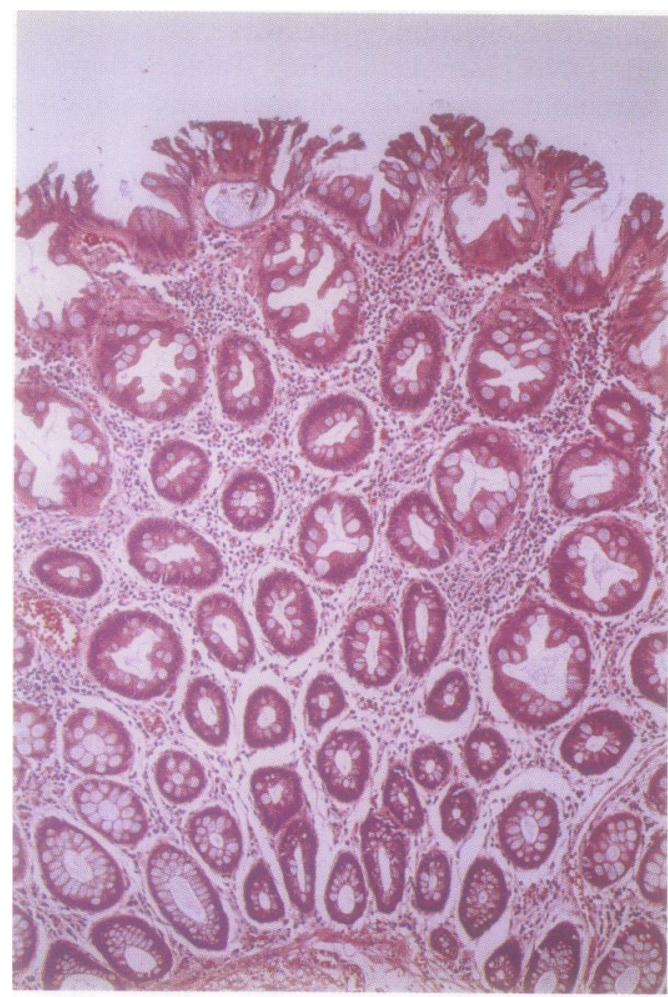

A

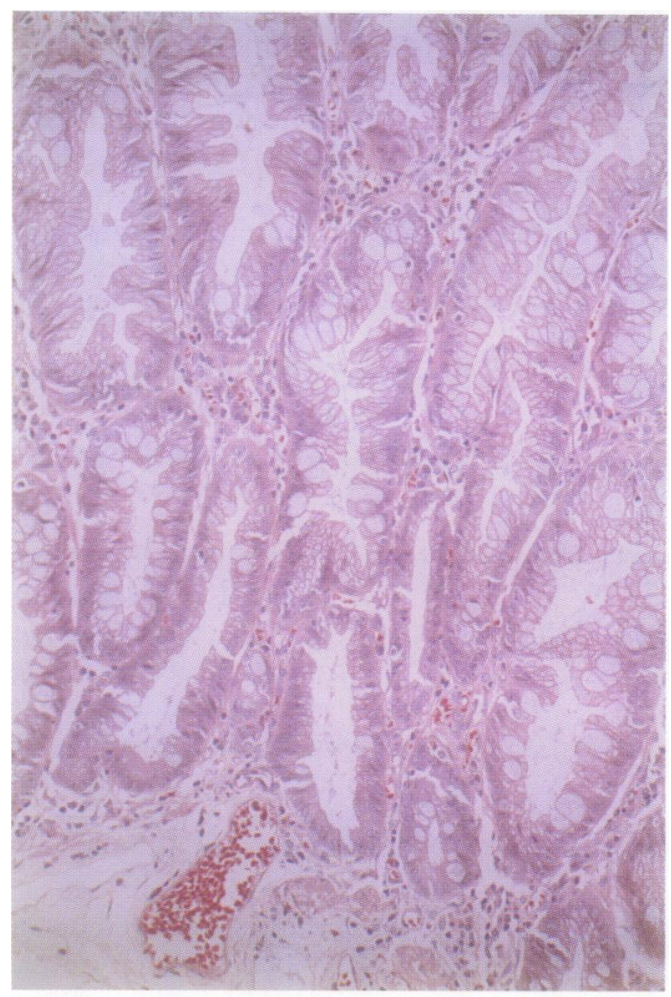

C

This transition from hyperplastic polyps to colorectal tumours is supported by previous reports based on histological findings. ${ }^{1-10}$ The coexistence of hyperplastic, adenomatous, or carcinomatous components in the same polyps was shown in these reports. None of the hyperplastic polyp nuclei contained accumulated $\mathrm{p} 53$ protein. The $\mathrm{p} 53$ gene mutation may be responsible for carcinogenesis of the colon and rectum at a late stage. Moreover, there was

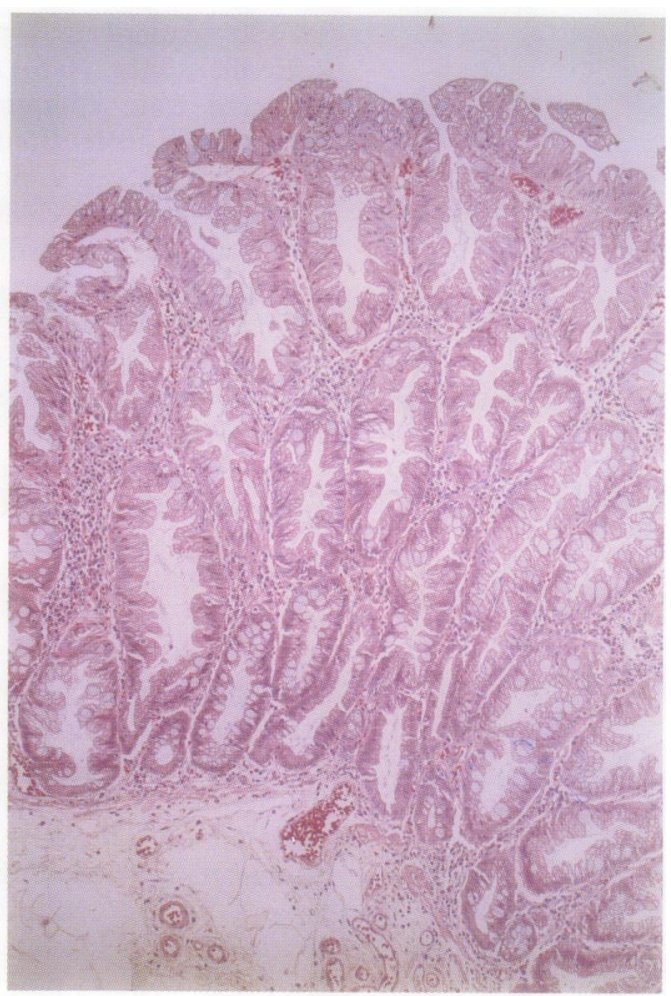

B

Hyperplastic polyps: microscopic views of vertical axis, stained with haematoxylin and eosin (original magnification $A, B \times 100, C \times 200)$. Case $9(A)$ harbours a $K$-ras mutation, case $19(B, C)$ has no $K$-ras mutation.

no APC mutation present in seven colorectal hyperplastic polyps. In addition to K-ras mutation, some unknown genetic alterations are probably needed for hyperplastic polyps to develop into colorectal neoplasms. In this study, there was no difference in size between hyperplastic polyps with K-ras mutation and those without. We investigated the relation between hyperlastic polyps harbouring K-ras mutation and their pit patterns. There was no 
correlation between $\mathrm{K}$-ras mutation and the pit pattern. Almost all of the hyperplastic polyps contained small or large asteroid pits. Therefore, by endoscopy hyperplastic polyps harbouring K-ras mutation were indistinguishable from those without K-ras mutation. Histologically, slight differences in the nuclear morphology of cryptic cells were found in hyperplastic polyps (Figure). A precise analysis of the histological features in hyperplastic polyps is needed. Hyperplastic polyps have not been regarded as precancerous lesions, because there was no evidence that the lesions were directly linked to colorectal neoplasia. However, it is now clear that about half of all hyperplastic polyps harbour K-ras mutation, and it is necessary to examine thoroughly the proposed hyperplasia-adenoma-adenocarcinoma sequence.

We thank Dr Tadakazu Shimoda, Clinical Laboratory, National Cancer Center Hospital, for suggestions of histological typing. This work was supported in part by a grant-in-aid for the second term of the comprehensive 10 year strategy for cancer control term of the comprehensive 10 year strategy for cancer control
from the Ministry of Health and Welfare, and a grant-in-aid from the Ministry of Health and Welfare, and a grant-in-aid from the Ministry of Education, Science and Culture of Japan. KO was awarded a research resident fellowshion
Foundation for Promotion of Cancer Research.

1 Arthur JF. Structure and significance of metaplastic nodules in the rectal mucosa. 7 Clin Pathol 1968; 21: 735-43.

2 Fenoglio $\mathrm{CH}$, Lane NT. The anatomical precursor of colorectal carcinoma. Cancer 1974; 34: 819-23.

3 Bengoecha O, Martinez-Penuela JM, Larrinaga B, Valerdi J Borda F. Hyperplastic polyposis of the colorectum and adenocarcinoma in a 24-year-old man. Am $\mathcal{F}$ Surg Patho 1987; 11: 323-7.

4 Urbanski SJ, Kossakowska AE, Marcon N, Bruce WR. Mixed hyperplastic adenomatous polyps - an underdiagnosed entity. Am $\mathcal{F}$ Surg Pathol 1984; 8: 551-6.

5 Cooper HS, Patschefsky AS, Marks G. Adenomatous and carcinomatous changes within hyperplastic colonic epithelium. Dis Colon Rectum 1979; 22: 152-6.
6 Estrada RE, Spuji HJ. Hyperplastic polyps of the large bowel. Am f Surg Pathol 1980; 4: 127-33.

7 Franzin G, Dina R, Zamboni G, Iannucci A, Scarpa A Novelli P. Hyperplastic (metaplastic) polyps of the colon Am ₹ Surg Pathol 1984; 8: 687-98.

8 Sumner HW, Wasserman NF, McClain CJ. Giant hyperplastic polyposis of the colon. Dig Dis Sci 1981; 26: 85-9.

9 Williams GT, Arthur JF, Bussey HJR, Morson BC. Metaplastic polyps and polyposis of the colorectum. Histopathology 1980; 4: 155-70.

10 Longacre TA, Fenoglio-Preiser CM. Mixed hyperplastic adenomatous polyps/serrated adenomas. Am $₹$ Surg Pathol 1990; 14: 524-37.

11 Fearon RE, Vogelstein B. A genetic model for colorectal tumorigenesis. Cell 1990; 61: 759-67.

12 Kudo S, Hirota S, Nakajima T, Hosobe S, Kusaka $H$ Kobayashi T, et al. Colorectal tumours and pit pattern. f Clin Pathol 1994; 47: 880-5.

13 Jass JR, Sobin LH. Histological typing of intestinal tumors. Geneva: World Health Organisation, 1989.

14 Mimamoto $T$, Sawaguchi $K$, Mai $M$, Yamashita $N$, Sugimura $T$, Esumi $H$. Infrequent $K$-ras activation in superficial-type (flat) colorectal adenomas and adenocarcinomas. Cancer Res 1994; 54: 2841-4.

15 Otori K, Sugiyama K, Hasebe H, Fukushima S, Esumi H Emergence of adenomatous aberrant crypt foci (ACF) from hyperplastic ACF with concomitant increase in cell from hyperplastic ACF with concomitant inct

16 Yanagisawa A, Ohtake K, Ohnishi K, Hori M, Kitagawa T, Sugano $\mathrm{H}$, et al. Frequent c-Ki-ras oncogene activation in mucous cell hyperplasia of pancreas suffering from chronic inflammation. Cancer Res 1993; 53: 953-6.

17 Caldas C, Hahn SA, Hruban RH, Redston MS, Yeo CJ Kern SE. Detection of K-ras mutations in the stool of patients with pancreatic adenocarcinoma and pancreatic ductal hyperplasia. Cancer 1994; 54: 3568-73.

18 DiGiuseppe JA, Hruban RH, Offerhaus GJ, Clement $\mathrm{MJ}$ van den Berg FM, Cameron JL, et al. Detection of K-ras mutations in mucinous pancreatic duct hyperplasia from mutations in mucinous pancreatic duct hyperplasia from a patient with a family history

19 Tada M, Ohashi M, Shiratori Y, Okudaira T, Komatsu Y, Kawabe $\mathrm{T}$, et al. Analysis of K-ras gene mutation in hyperplastic duct cells of the pancreas without pancreatic disease. Gastroenterology 1996; 110: 227-31.

20 Skinner JM, Whitehead JR. Tumor-associated antigen in polyps and carcinoma of the human large bowel. Cancer 1981; 47: 1241-5.

21 Jass JR, Filipe MI, Abbas S, Falcon CAJ, Wilson Y, Lovell D. A morphological and histochemical study of metaplastic polyps of the colorectum. Cancer 1984; 53: 510-5.

22 Bronner MP, Culin C, Reed JC, Furth EE The bcl-2 protooncogene and the gastrointestinal epithelial tumor progression model. Am $\mathcal{f}$ Pathol 1995; 146: 20-6. 